\title{
Smoking, HIV, and risk of pregnancy loss
}

\author{
Daniel Westreich ${ }^{a}$, Jordan Cates ${ }^{a}$, Mardge Cohen ${ }^{b}$, \\ Kathleen M. Weber ${ }^{c}$, Dominika Seidmand, Karen Cropsey ${ }^{\mathrm{e}}$, \\ Rodney Wright ${ }^{\mathrm{f}}$, Joel Milam ${ }^{\mathrm{g}}$, Mary A. Young ${ }^{\mathrm{h}}$, C. Christina Mehta ${ }^{\mathrm{i}}$, \\ Deborah R. Gustafson ${ }^{j}$, Elizabeth T. Golub ${ }^{k}$, \\ Margaret A. Fischl' and Adaora A. Adimora ${ }^{a, m}$
}

Objective: Cigarette smoking during pregnancy increases risks of poor pregnancy outcomes including miscarriage and stillbirth (pregnancy loss), but the effect of smoking on pregnancy loss among HIV-infected women has not been explored. Here, investigated the impact of smoking on risk of pregnancy loss among HIV-positive and HIV-negative women, and estimated the potential impact of realistic smoking cessation interventions on risk of pregnancy loss among HIV-positive women.

Design: We analyzed pregnancy outcomes in HIV-positive and HIV-negative participants in the Women's Interagency HIV Study between 1994 and 2014.

Methods: We estimated effects of current smoking at or immediately before pregnancy on pregnancy loss; we controlled for confounding using regression approaches, and estimated potential impact of realistic smoking cessation interventions using a semiparametric g-formula approach.

Results: Analysis examined 1033 pregnancies among 659 women. The effect of smoking on pregnancy loss differed dramatically by HIV status: adjusted for confounding, the risk difference comparing current smokers to current nonsmokers was $19.2 \%$ (95\% confidence limit $10.9-27.5 \%)$ in HIV-positive women and $9.7 \%(95 \%$ confidence limit $0.0-19.4 \%$ ) in HIV-negative women. These results were robust to sensitivity analyses. We estimated that we would need to offer a realistic smoking cessation intervention to 36 women to prevent one pregnancy loss.

Conclusion: Smoking is a highly prevalent exposure with important consequences for pregnancy in HIV-positive pregnant women in the United States, even in the presence of potent highly active antiretroviral therapy. This evidence supports greater efforts to promote smoking cessation interventions among HIV-positive women, especially those who desire to become pregnant.

Copyright @ 2017 The Author(s). Published by Wolters Kluwer Health, Inc.

AIDS 2017, 31:553-560

Keywords: epidemiology, HIV, pregnancy loss, smoking, women's health

${ }^{a}$ Department of Epidemiology, UNC-Chapel Hill, Chapel Hill, North Carolina, bepartment of Medicine, John H. Stroger, Jr. Hospital of Cook County and Rush Medical College, ${ }^{C}$ Hektoen Institute of Medicine/The CORE Center, Cook County Health \& Hospital Systems, Chicago, Illinois, ${ }^{\mathrm{d} D e p a r t m e n t}$ of Obstetrics, Gynecology \& Reproductive Health Services, University of California San Francisco, San Francisco, California, e Department of Psychiatry and Behavior Neurobiology, University of Alabama Birmingham, Birmingham, Alabama, 'A Albert Einstein College of Medicine, Montefiore Medical Center, New York, New York, ${ }^{g}$ Department of Preventive Medicine, University of Southern California, Los Angeles, California, ${ }^{\mathrm{h}}$ Division of Infectious Diseases, Georgetown University, Washington, District of Columbia, 'Department of Biostatistics and Bioinformatics, Emory University, Atlanta, Georgia, 'State University of New York Downstate Medical Center, Brooklyn, New York, ${ }^{\mathrm{k}}$ Department of Epidemiology, Johns Hopkins Bloomberg School of Public Health, Baltimore, Maryland, 'Division of Infectious Diseases, University of Miami Miller School of Medicine, Miami, Florida, and ${ }^{m}$ Department of Medicine, UNC-Chapel Hill, Chapel Hill, North Carolina, USA. Correspondence to Daniel Westreich, Department of Epidemiology, CB 7435 McGavran-Greenberg Hall, Chapel Hill, NC, 27599, USA.

Tel: +1919966 7437; e-mail: djw@unc.edu

Received: 14 July 2016; revised: 24 October 2016; accepted: 31 October 2016. 


\section{Introduction}

Cigarette smoking during pregnancy is a risk factor for poor pregnancy outcomes including low birthweight, stillbirth, and neonatal morbidity and mortality $[1,2]$. Evidence demonstrating an association between cigarette smoking and miscarriage (spontaneous abortion) is less well established but strong: the surgeon general said in 2014 that the 'evidence is suggestive, but not sufficient, to infer a causal relationship between maternal active smoking and spontaneous abortion' [1]. A recent meta-analysis found that risk of miscarriage (defined as pregnancy loss up to 28 weeks gestation) among women who smoked during pregnancy was 1.32 (95\% confidence limit 1.21-1.44) times the risk among nonsmoking women, with increasing risks associated with increased cigarette consumption [3]. These results are consistent with the results of earlier metaanalyses $[4,5]$. The biological mechanism explaining how smoking might lead to miscarriage remains unclear [1], but hypotheses include fetal hypoxia and changes in placental vasculature [6-9], inflammation [10-14], and immune modulation $[13,15]$.

Smoking is highly prevalent among women living with HIV in the United States. A recent large-scale study found that approximately $35 \%$ of women receiving HIV care in the US report current smoking, about twice the prevalence in the general population [16]. In addition, women with HIV infection may be less likely to cease smoking than other women [17].

Women living with HIV are now being diagnosed and initiated on treatment earlier, which has resulted in longer life expectancy, healthier lives, and a significantly decreased rate of mother-to-child transmission. This has influenced conception choices and pregnancy rates among HIV-positive women [18]. However, HIV infection has been associated with an increased risk of miscarriage [19] potentially due to chronic inflammation associated with long-term HIV infection or effects of HIV on the immune system [18,20,21].

Given that both HIV infection and smoking are associated with inflammation and immune activation [22-24], it is plausible that HIV and smoking might interact to place HIV-infected women who smoke at higher-than-expected risk for miscarriage. To date, there has been little research examining the effect of smoking on pregnancy loss among HIV-infected women. Although the causes of miscarriage among HIV-infected women were previously examined in the Women's Interagency HIV Study (WIHS) [20], effect of smoking on miscarriage was not explicitly investigated. A recent report demonstrated increased morbidity among infants of HIV-positive smokers compared with those of HIV-positive nonsmokers, but this study did not examine miscarriage [2] nor did a study that found positive associations between smoking and adverse birth outcomes [25].
Here, we investigated the effect of smoking on risk of miscarriage or stillbirth (hereafter, pregnancy loss) among participants of the WIHS from 1994 until 2014. We also examined differences in the effects of smoking on pregnancy loss by HIV status. Finally, we quantified the potential impact of a realistic intervention for smoking cessation on total rates of pregnancy loss [26-28]. Notably, recent research in the WIHS found that pregnancy is associated with a decreased time to smoking cessation [27], pointing toward the potential for effective interventions in this population.

\section{Methods}

\section{Main data source}

The WIHS is a multicenter prospective observational cohort study of HIV-positive and sociodemographically matched HIV-negative women enrolled in 10 cities throughout the United States. WIHS participants undergo twice-yearly medical examinations and interviews; detailed procedures are described elsewhere $[29,30]$. WIHS enrollment occurred after approval by each site's institutional review board and the WIHS Executive Committee. All participants provided written informed consent. These analyses were reviewed and approved by the UNC Office of Human Research Ethics.

\section{Outcome, exposure, covariates}

The primary objective was to examine whether the impact of smoking on pregnancy loss in the WIHS cohort differed by HIV status. Smoking, HIV status, and birth outcomes were obtained from the study database.

WIHS participants were eligible for this study if they reported miscarriage (pregnancy loss before 20 weeks), stillbirth, or live birth at a study visit between 1994 and 2014. Pregnancy outcomes coded as therapeutic abortion (32\% of outcomes), ectopic pregnancy (3\%), other $(1 \%)$, or missing (including responses skipped, refused, or answered as 'Don't know', 1\%) were excluded as uninformative for the purpose of assessing the effect of smoking on the pregnancy loss.

The main exposure for this study was cigarette smoking during or immediately prior to pregnancy, which we referred to as 'current cigarette smoking'. To capture this exposure, we used self-reported smoking status recorded at the visit immediately prior to the visit at which the pregnancy outcome was documented. This lagging of the exposure ensured that the exposure preceded the outcome in time; however, note that this visit was between approximately $0-6$ months before the pregnancy outcome, and may or may not have been during pregnancy. When this one-back visit was missing (because the participant missed a WIHS visit) we took smoking status from the two-back visit; when the one-back and two-back visits were missing, we took the smoking status 
from the visit at which pregnancy outcome was recorded (zero-back). Implications of this coding scheme were examined in sensitivity analysis (see below).

Additional covariates likely to confound the exposureoutcome relationships of interest were identified through use of a causal directed acyclic graph [31]. Fully adjusted models controlled for HIV status, age, race, employment status, above-median income, BMI, depression, and recent use of intravenous and nonintravenous drugs, marijuana, and alcohol. These variables were all captured at the same visit as the exposure information was captured, and were generally modeled as categorical variables; age and BMI were modeled as restricted quadratic splines [32]. In sensitivity analysis, we examined impact of specific nonintravenous drugs (see below).

We did not adjust for a history of smoking prior to main exposure in the main analyses because among women without a history of smoking, only two women reported smoking during pregnancy; thus, there were near-empty cells in the table of smoking history and current smoking [33]. However, in sensitivity analyses we restricted the sample to only those women with a history of smoking to examine the possible impact of smoking history on pregnancy loss via sustained inflammatory and metabolic effects $[34,35]$. We also did not control for history of pregnancy loss in the main analyses: smoking exposure during prior pregnancies was not available for reported pregnancies occurring prior to WIHS enrollment, and controlling for prior outcomes without controlling for prior exposure might increase rather than decrease bias [36]. We included an indicator of a history of miscarriage in a sensitivity analysis. We did not control for bacterial vaginosis in main analysis, because smoking appears to increase risk of this condition, and thus this condition seems more likely to be a mediator of the smokingpregnancy loss relationship than a confounder [37]; however, we controlled for bacterial vaginosis concurrent with smoking exposure in a sensitivity analysis. Finally, very few of these pregnancies were exposed to diabetes or common sexually transmitted infections (STIs) (gonorrhea, chlamydia, syphilis) so these potential confounders were not included in models.

\section{Main analyses}

The two main analyses were the total impact of smoking on pregnancy loss among all women (analysis 1) and stratifying by HIV infection status (analysis 2).

\section{Sensitivity analyses}

We conducted several sensitivity analyses. We restricted analysis to only those women with a documented history of smoking, and extended this analysis to control for any history of miscarriages or stillbirths. We considered main effects overall and by HIV status among 327 women who reported no prior pregnancies of any kind during or previous to participation in the WIHS. We limited to more-recent pregnancies (pregnancies since 1998; pregnancies since 2002) to explore time-sensitivity of results. We examined the impact of adjustment for presence of bacterial vaginosis. Additionally, among HIV-positive women, we examined effect measure modification by use of any ART and separately by use of HAART, and by viral suppression status controlling for HAART use. We also analyzed restricting to individuals with exposure and covariates measured exactly one visit before the pregnancy outcome, to minimize measurement error; and separately restricting to individuals with exposure and covariates measured exactly two visits before the pregnancy outcome, to clarify sensitivity of the results to exposure timing. Finally, we adjusted for recent use of cocaine and methamphetamine, rather than for nonintravenous drugs in general. In general, sensitivity analyses adjusted for a reduced set of confounders to ensure model convergence.

\section{Statistical approach}

For all analyses, we used multiple linear regression to estimate adjusted risk differences for the risk of pregnancy loss comparing current smokers to current nonsmokers among WIHS participants, both overall and by HIV infection status. We focus primarily on the estimation of risk differences rather than risk or odds ratios because we are primarily interested in population impact of smoking on pregnancy loss; it is generally thought that absolute measures such as risk differences quantify impact better than ratio measures [38-40]. We controlled for all variables noted above; when the resulting model did not converge, we used backwards elimination methods to reduce the model to key confounders. All models allowed multiple pregnancies/outcomes per woman; we used a generalized estimating equations approach with an exchangeable correlation structure to account for within-woman correlations.

\section{Population intervention analyses}

The analyses described above attempt to estimate causal effect of smoking exposures, but do not map directly onto potential interventions to reduce impact of smoking in the population $[26,28,41]$. We estimate several additional risk differences that point toward effects of interventions on smoking among HIV-positive women (only) in this setting. Specifically, we estimate a population attributable risk difference, which contrasts the risk of pregnancy loss observed in the data to a population in which, counter to fact, no women reported current smoking. Then we estimate a generalized intervention risk difference, which contrasts the risk of pregnancy loss observed in the data to a population in which current smoking is reduced by means of a smoking cessation intervention, which could be broadly implemented under real-world conditions. Specifically, we estimated the expected impact of applying the intervention described by Hoffman et al. [42] and tested in the WIHS population by Redding et al. [43], which yielded a quit rate of $13.6 \%$. These analyses 


\begin{tabular}{|c|c|c|}
\hline Characteristic & $\begin{array}{l}\text { Current smoker } \\
\quad n=377\end{array}$ & $\begin{array}{c}\text { Current nonsmoker } \\
n=656\end{array}$ \\
\hline \multicolumn{3}{|l|}{ Demographic } \\
\hline Age (years) ${ }^{a}$ & $30.2(25.6,34.8)$ & $28.7(24.6,32.5)$ \\
\hline Black race & $253(67 \%)$ & $372(57 \%)$ \\
\hline Hispanic ethnicity & $86(23 \%)$ & $223(34 \%)$ \\
\hline \multicolumn{3}{|l|}{ Socioeconomic status } \\
\hline Employed & $74(20 \%)$ & $267(41 \%)$ \\
\hline $\begin{array}{l}\text { Currently has health } \\
\text { insurance }\end{array}$ & $300(80 \%)$ & $569(87 \%)$ \\
\hline Income above median & $116(31 \%)$ & $355(54 \%)$ \\
\hline $\begin{array}{l}\text { Completed high } \\
\text { school }\end{array}$ & $200(53 \%)$ & $401(61 \%)$ \\
\hline \multicolumn{3}{|l|}{ Substance use } \\
\hline $\begin{array}{l}\text { History of smoking } \\
\text { (years) }^{\mathrm{a}}\end{array}$ & $14.4(9.2,19.1)$ & $0(0,3.4)$ \\
\hline \multicolumn{3}{|l|}{ Since last visit } \\
\hline $\begin{array}{l}\text { Alcohol consumption } \\
\text { (any) }\end{array}$ & $166(44 \%)$ & $173(26 \%)$ \\
\hline Intravenous drug use & $8(2 \%)$ & $4(1 \%)$ \\
\hline $\begin{array}{l}\text { Nonintravenous drug } \\
\text { use }\end{array}$ & $145(38 \%)$ & $78(12 \%)$ \\
\hline Marijuana use & $114(30 \%)$ & $70(11 \%)$ \\
\hline $\begin{array}{l}\text { Intravenous drug use at } \\
\text { baseline }{ }^{b}\end{array}$ & $63(17 \%)$ & $34(5 \%)$ \\
\hline \multicolumn{3}{|l|}{ Clinical indicators } \\
\hline HIV-positive & $212(56 \%)$ & $380(58 \%)$ \\
\hline $\begin{array}{l}\text { Number of previous } \\
\text { pregnancies }^{\mathrm{a}}\end{array}$ & $1.0(1.0,2.0)$ & $1.5(1.0,2.0)$ \\
\hline $\mathrm{BMI}^{\mathrm{a}}$ & $27.4(23.4,32.9)$ & $29.2(25.4,34.0)$ \\
\hline $\begin{array}{l}\text { Depression (CESD } \geq \\
\text { 16) }\end{array}$ & $166(44 \%)$ & $159(24 \%)$ \\
\hline Bacterial vaginosis & $77(20 \%)$ & $57(9 \%)$ \\
\hline
\end{tabular}

Data represent 1033 outcomes among 659 individual participants. CESD, Center for Epidemiologic Studies Depression (Scale). Table contents are counts (\%) except.

aReported as median (Q1, Q3).

${ }^{\mathrm{b}}$ Reported as HIV risk category even among women without HIV.

were performed using the parametric g-formula, a statistical method that can be used to simulate cohort experiences under well defined interventions $[28,44,45]$. We validated that the g-formula fit while ignoring repeated measures gave similar results compared with the main analysis; for computational simplicity we proceeded ignoring repeated measures.

\section{Results}

There were 1033 pregnancies with outcomes of live birth, stillbirth, or miscarriage reported among 659 women in the WIHS between 1994 and 2014. Characteristics of WIHS participants before or at the time of pregnancy by current smoking status are shown in Table 1. Current smokers during pregnancy were more likely to be black and to be unemployed, and less likely to have completed high school than women who did not smoke during pregnancy. In addition, smokers were far more likely than nonsmokers to report recent alcohol and nonintravenous drug use including marijuana. depressive symptoms
[Center for Epidemiologic Studies Depression (Scale) $\geq 16]$ were twice as common among smokers compared with nonsmokers. HIV status was similar for women who smoked and women who did not smoke during pregnancy. Only six women reported diabetes at the visit previous to pregnancy outcome.

Characteristics of HIV-positive women $(n=396)$ at the time of their 592 pregnancies are described in Table 2. Similar to findings for the combined study sample, HIVpositive pregnant women who currently smoked were also more likely to report recent alcohol consumption and nonintravenous drug use compared with HIV-positive pregnant women who did not smoke. HIV-positive women who smoked during pregnancy were also less likely to report current use of antiretroviral therapy and were less likely to be virally suppressed.

Thirty-two percent of all pregnancies in the study sample resulted in pregnancy loss, including 314 miscarriages and 12 stillbirths. The effect of smoking on risk of pregnancy loss is reported in Table 3. Adjusted for confounding, the estimated risk difference of current smoking on risk of miscarriage was $15.1 \%$ (95\% confidence limit $8.4-$ $21.9 \%$ ), indicating that current smokers were $15 \%$ more likely to report a miscarriage compared to current nonsmokers (Table 3 ). These effects were largely robust to sensitivity analysis, and appeared slightly higher among women with a history of smoking (Table 3).

The overall risk of pregnancy loss was similar by HIV status: 30\% among HIV-negative women, and 33\% among HIV-positive women. In smoking-unexposed pregnancies, unadjusted (crude) risk of pregnancy loss was approximately the same in HIV-positive and HIVnegative women (22 and 25\%, respectively), whereas in smoking-exposed pregnancies, crude risk of pregnancy loss was higher in HIV-positive women (52\%) than in HIV-negative women (33\%).

Consistent with these crude findings, the adjusted effect of smoking on pregnancy loss differed dramatically by HIV status (Table 4; interaction $P=0.1169$ ): the adjusted risk difference for smokers vs. not nonsmokers was larger in HIV-positive women (risk difference $=19.2 \%$; 95\% confidence limit 10.9-27.5\%) than HIV-negative women (risk difference $=9.7 \%, 95 \%$ confidence limit 0.0-19.4\%) (Table 4). Women living with HIV, women on HAART, and separately virally suppressed women (controlling for use of HAART) experienced larger impacts of smoking on pregnancy loss; results were also higher among women with a history of smoking (Table 4). Results were largely robust to sensitivity analyses, including restriction to women with exposure measured one visit, or alternatively two visits, before pregnancy outcome (not shown) and when controlling for cocaine or methamphetamine use rather than nonintravenous drugs in general (not shown). For comparison with 
Table 2. Selected characteristics of 592 pregnancies among 396 HIV-positive women participating in the Women's Interagency HIV Study between 1994 and 2014, measured before or at pregnancy outcome. ${ }^{a}$

\begin{tabular}{lcc}
\hline Characteristic & Current smoker $n=212$ & Current nonsmoker $n=380$ \\
\hline Substance use since last visit & & \\
Alcohol consumption (any) & $89(42 \%)$ & $81(21 \%)$ \\
Intravenous drug use & $4(2 \%)$ & $3(1 \%)$ \\
$\quad$ Nonintravenous drug use & $76(36 \%)$ & $31(8 \%)$ \\
$\quad$ Marijuana use & $52(25 \%)$ & $28(7 \%)$ \\
Clinical indicators & $141(67 \%)$ & $305(80 \%)$ \\
$\quad$ Current use of ART & $96(45 \%)$ & $258(68 \%)$ \\
$\quad$ Current use of HAART & $102(48 \%)$ & $270(71 \%)$ \\
Viral load <1000 copies/ml & $412(283,599)$ & $485(325,679)$ \\
CD4 cell count (cells/ $\mu l ;$ most recent) & \\
\hline
\end{tabular}

Table contents are counts (\%) except. Clinical indicators measured concurrently with smoking exposure.

${ }^{\mathrm{a}}$ Reported as median (Q1, Q3).

previous work, we also calculated the adjusted risk ratios for the effect of smoking on pregnancy loss: in HIVnegative women, the risk ratio was 1.31 (95\% confidence limit $0.99-1.75$ ) and in HIV-positive women the risk ratio was 1.74 (95\% confidence limit 1.36-2.23).

\section{Population intervention estimates}

The overall risk of miscarriage in the 592 women living with HIV was 33\%. We then estimated among women living with HIV, the population attributable risk difference comparing the observed data with a hypothetical population in which no one smoked was $6.8 \%(95 \%$ confidence limit 3.3-10.4\%). The risk difference comparing risk of pregnancy loss in the observed data

Table 3. Impact of smoking status (current smokers vs. current nonsmoker) on risk of miscarriage or stillbirth among Women's Interagency HIV Study participants, 1994-2014.

\begin{tabular}{|c|c|c|}
\hline $\begin{array}{l}\text { Analysis 1: } \\
\text { total WIHS }\end{array}$ & $\begin{array}{c}\text { Risk } \\
\text { difference (\%) }\end{array}$ & $\begin{array}{l}95 \% \text { confidence } \\
\text { limits }(\%)\end{array}$ \\
\hline Crude & 23.6 & $17.1-30.0$ \\
\hline Adjusted $^{\mathrm{a}}$ & 15.1 & $8.4-21.9$ \\
\hline Sensitivity analyses ${ }^{b}$ & & \\
\hline Adjusted, reduced model ${ }^{\mathrm{b}}$ & 15.8 & $9.3-22.4$ \\
\hline $\begin{array}{l}1.1 \text { Subjects with } \\
\text { smoking history }\end{array}$ & 19.1 & $11.4-26.8$ \\
\hline $\begin{array}{l}1.2 \text { Subjects with smoking } \\
\text { history and control } \\
\text { for previous } \\
\text { pregnancy loss }\end{array}$ & 18.8 & $11.2-26.4$ \\
\hline $\begin{array}{l}\text { 1.3 First pregnancy } \\
\text { 1.4 Pregnancies on or after }\end{array}$ & 15.6 & $4.9-26.2$ \\
\hline 1 January 1998 & 12.6 & $5.1-20.1$ \\
\hline 1 January 2002 & 14.4 & $5.9-23.0$ \\
\hline $\begin{array}{l}1.5 \text { Controlling for } \\
\text { bacterial vaginosis }\end{array}$ & 14.1 & $7.7-20.5$ \\
\hline
\end{tabular}

All models account for repeated outcomes within women. WIHS, Women's Interagency HIV Study.

a Fully adjusted models controlled for HIV status, age, socioeconomic status (employment, race, income), BMI, depression, recent use of intravenous drugs, marijuana, and alcohol. Modeling details given in text.

${ }^{b}$ Sensitivity analyses relied on a reduced model for convergence. The main reduced adjusted model controlled for HIV status, depression, recent use of marijuana and alcohol. with the risk in a hypothetical population in which current smoking was less prevalent by approximately $14 \%$ points due to a realistic smoking cessation intervention was $1.0 \%(0.4-1.7 \%)$.

\section{Discussion}

This study estimates the effects of smoking prior to or early in pregnancy on risk of pregnancy loss (primarily miscarriage) among HIV-positive as well as HIV-negative pregnant women. We found strong evidence that current smoking at the visit prior to pregnancy increased risk of pregnancy loss in both HIV-positive and HIV-negative women. We also found that the effect of smoking was substantially stronger among HIV-positive women, a finding robust to sensitivity analysis. We note that the $P$ value for the statistical interaction of smoking and HIV did not reach significance at an $\alpha$ of 0.05 in main analysis; however, we were more concerned with estimation of effect size than with testing significance in this work $[46,47]$.

One possible explanation for the strong effect of smoking on pregnancy loss risk among HIV-positive women is synergism due to inflammation, which is characteristic of both smoking and long-term HIV infection, although other results (Table 4) complicate this explanation. The lack of clear mechanism by which smoking apparently dramatically increases risks of pregnancy loss points toward future areas of research.

Nonetheless, in the present data we can consider to what extent smoking cessation interventions could reduce incidence of pregnancy loss in this population. Here, we calculated risk differences for smoking cessation interventions among HIV-positive women in the WIHS. Under the assumption that the intervention of Hoffman et al. [42] would work similarly in other WIHS sites as it did in Chicago [43], we calculated that universal application of this intervention could result in a risk difference of about $1.0 \%$ in the entire population. In the WIHS, for every 100 pregnancies, about $(212 / 592=) 36$ 
Table 4. Impact of smoking status (current smoking, yes/no) on risk of miscarriage or stillbirth among Women's Interagency HIV Study participants, 1994-2014, by HIV status.

\begin{tabular}{|c|c|c|c|c|}
\hline \multirow[b]{2}{*}{$\begin{array}{l}\text { Analysis 2: by } \\
\text { HIV status }\end{array}$} & \multicolumn{2}{|c|}{ HIV-negative } & \multicolumn{2}{|c|}{ HIV-positive } \\
\hline & $\begin{array}{c}\text { Risk } \\
\text { difference }(\%)\end{array}$ & $\begin{array}{l}\text { 95\% confidence } \\
\text { limits }\end{array}$ & $\begin{array}{c}\text { Risk } \\
\text { difference (\%) }\end{array}$ & $\begin{array}{l}\text { 95\% confidence } \\
\text { limits }\end{array}$ \\
\hline Crude & 15.0 & 4.9 to 25.1 & 30.0 & 21.9 to 38.2 \\
\hline Adjusted $^{\mathrm{a}}$ & 9.7 & 0.0 to 19.4 & 19.2 & 10.9 to 27.5 \\
\hline \multicolumn{5}{|l|}{ Sensitivity analyses ${ }^{b}$} \\
\hline Adjusted, reduced model ${ }^{b}$ & 8.8 & -0.9 to 18.5 & 21.5 & 13.3 to 29.8 \\
\hline 2.1 Subjects with smoking history & 14.2 & 3.0 to 25.4 & 24.0 & 14.1 to 33.9 \\
\hline $\begin{array}{l}2.2 \text { Subjects with smoking history and } \\
\text { control for previous pregnancy loss }\end{array}$ & 13.0 & 2.6 to 23.4 & 23.9 & 14.0 to 33.7 \\
\hline 2.3 First pregnancy & 7.3 & -7.7 to 22.3 & 23.5 & 9.7 to 37.2 \\
\hline \multicolumn{5}{|l|}{ 2.4 Pregnancies on or after ... } \\
\hline 1 January 1998 & 4.2 & -6.4 to 14.8 & 19.7 & 9.9 to 29.5 \\
\hline 1 January 2002 & 5.5 & -6.4 to 17.4 & 23.7 & 12.6 to 34.8 \\
\hline 2.5 Controlling for bacterial vaginosis & 8.0 & -1.5 to 17.5 & 19.2 & 11.0 to 27.3 \\
\hline \multicolumn{5}{|l|}{2.6 By ART use } \\
\hline Current ART & & & 20.4 & 10.4 to 30.5 \\
\hline No current ART & & & 17.5 & 1.9 to 33.1 \\
\hline \multicolumn{5}{|l|}{ 2.7 By HAART use ${ }^{\mathrm{C}}$} \\
\hline Current HAART & & & 24.0 & 13.0 to 35.1 \\
\hline No current HAART & & & 13.4 & 0.4 to 26.5 \\
\hline \multicolumn{5}{|l|}{2.8 By viral suppression status ${ }^{\mathrm{d}}$} \\
\hline Suppressed & & & 22.5 & 11.1 to 33.9 \\
\hline Not suppressed & & & 13.4 & 0.6 to 26.3 \\
\hline
\end{tabular}

All models account for repeated outcomes within women.

aFully adjusted models controlled for HIV status (including an interaction term with main exposure), age, socioeconomic status (employment, race, income), BMI, depression, recent use of intravenous drugs, marijuana, and alcohol. Modeling details given in text.

${ }^{b}$ Sensitivity analyses relied on a reduced model for convergence. The main reduced adjusted model controlled for HIV status (including an interaction term with main exposure), depression, recent use of marijuana and alcohol.

${ }^{\mathrm{C}}$ This model did not control for viral load or $\mathrm{CD} 4{ }^{+}$cell count, which are affected by ART/HAART use in the last six months.

${ }^{\mathrm{d}}$ Model also controlled for use of HAART. Suppression was defined as a viral load $<1000$ copies/ml.

are in smokers. Since the intervention in question only applies to smokers, the number needed to treat is approximately 36 ; that is, applying this intervention to 36 smokers would result in one fewer miscarriage. This number needed to treat is based on critical assumptions including no uncontrolled confounding and correct model specification $[48,49]$, which cannot be verified empirically in observational data. As such, this estimate should be interpreted cautiously.

The interventional estimation also assumed that there were no relevant side-effects of smoking cessation, and that immediate smoking cessation at the visit previous to the pregnancy outcome will be sufficient to affect the pregnancy outcome. This latter assumption is especially important given recent findings in the WIHS that pregnancy is associated with a decreased time to smoking cessation [27]. We examined this assumption by looking only at HIV-positive women who reported current smoking two visits before pregnancy outcome $(n=170)$, we compared the 139 women who continued smoking to the 31 who reported no smoking at one visit before pregnancy outcome. While the results were imprecise due to small numbers, they were below the null. This suggests that short-term interventions might indeed be effective at removing substantial risk of pregnancy loss, although more work is needed to validate this claim.
Additional limitations include the following. Pregnancy losses are self-reported and it is likely that numerous early miscarriages were not reported and that some presumed miscarriages were not actual pregnancies. However, to negate the main findings of this study, smoking would have to be dramatically protective against early pregnancy losses, which seems unlikely [3]. Likewise, unmeasured confounding (e.g. smoking history, caffeine use, additional coinfections not addressed above) is a threat to our findings, but given their magnitude a confounder (or group of confounders) having this impact seems implausible. Another potential limitation of this work is external validity $[50,51]$. HIV-negative women in the WIHS are not necessarily representative of the general population of HIV-negative women, as participants with a history of drug use and other risk behaviors were recruited as controls in WIHS. However, the adjusted risk ratio for smoking calculated among HIV-negative women is 1.35 and is comparable to the recently reported metaanalytic estimate of 1.32 [3].

This analysis has numerous strengths. The WIHS is one of the largest and longest running studies of HIV-positive women in the world, and has well validated data collection procedures. Because of the ethical impossibility of randomizing smoking or HIV infection, such large prospective cohort studies are the gold standard for 
addressing the question we sought to answer in this report. Additionally, the inclusion of HIV-negative controls within the WIHS allowed us to directly estimate how smoking is modified by HIV infection. While there remain threats to the validity of every study - observational or randomized - our extensive sensitivity analyses support our main findings. Finally, our estimate of the potential effectiveness of a real-world intervention for smoking cessation is novel, and points to concrete next steps that could possibly address these issues more broadly.

In summary, we found that smoking is associated with large absolute increases in risk of pregnancy loss, that increases in risk are substantially larger among HIVpositive than HIV-negative women, and that realistic interventions can potentially lead to reduced incidence of pregnancy loss. Taken in concert with evidence from HIV-negative populations, this suggests that HIV-positive women planning a pregnancy should be strongly encouraged to cease smoking and supported in their efforts to do so, for their own health and to increase the probability of live birth.

\section{Acknowledgements}

The authors thank Dr Stephen R. Cole, PhD (Department of Epidemiology, UNC-Chapel Hill) for input on this work.

Author contribution: D.W. conceived the study, led data analysis, wrote first draft, and edited all drafts of the article; D.W. had full access to all of the data in the study and takes responsibility for the integrity of the data and the accuracy of the data analysis. J.C. assisted with data analysis, contributed to writing. M.C. and K.M.W. contributed to data collection/acquisition, advised on data analysis, contributed data, contributed to writing. D.S., K.C., R.W., J.M., M.A.Y., C.C.M., D.R.G., E.T.G., M.A.F., A.A.A. all contributed to data collection/acquisition, contributed to writing. All authors approved final version for submission.

Design and conduct of the study, analysis of the data, and preparation and review of this manuscript was supported by the Office of the Director and the Eunice Kennedy Shriver National Institute of Child Health \& Human Development of the National Institutes of Health (DP2HD-084070), by the National Institute of Allergy and Infectious Diseases through the UNC CFAR (P30-AI50410) and the National Institutes of Health through the UNC WIHS (U01-AI-103390; see also below). The content is solely the responsibility of the authors and does not necessarily represent the official views of the National Institutes of Health.

Collection, management, and interpretation of the data and approval of the manuscript was supported by the
WIHS. Data in this manuscript were collected by the Women's Interagency HIV Study (WIHS). The contents of this publication are solely the responsibility of the authors and do not represent the official views of the National Institutes of Health (NIH). WIHS (Principal Investigators): UAB-MS WIHS (Michael Saag, MirjamColette Kempf, and Deborah Konkle-Parker), U01-AI103401; Atlanta WIHS (Ighovwerha Ofotokun and Gina Wingood), U01-AI-103408; Bronx WIHS (Kathryn Anastos), U01-AI-035004; Brooklyn WIHS (Howard Minkoff and Deborah Gustafson), U01-AI-031834; Chicago WIHS (Mardge Cohen and Audrey French), U01-AI-034993; Metropolitan Washington WIHS (Mary Young and Seble Kassaye), U01-AI-034994; Miami WIHS (Margaret Fischl and Lisa Metsch), U01AI-103397; UNC WIHS (Adaora Adimora), U01-AI103390; Connie Wofsy Women's HIV Study, Northern California (Ruth Greenblatt, Bradley Aouizerat, and Phyllis Tien), U01-AI-034989; WIHS Data Management and Analysis Center (Stephen Gange and Elizabeth Golub), U01-AI-042590; Southern California WIHS (Joel Milam), U01-HD-032632 (WIHS I - WIHS IV). The WIHS is funded primarily by the National Institute of Allergy and Infectious Diseases (NIAID), with additional co-funding from the Eunice Kennedy Shriver National Institute of Child Health and Human Development (NICHD), the National Cancer Institute (NCI), the National Institute on Drug Abuse (NIDA), and the National Institute on Mental Health (NIMH). Targeted supplemental funding for specific projects is also provided by the National Institute of Dental and Craniofacial Research (NIDCR), the National Institute on Alcohol Abuse and Alcoholism (NIAAA), the National Institute on Deafness and other Communication Disorders (NIDCD), and the NIH Office of Research on Women's Health. WIHS data collection is also supported by UL1-TR000004 (UCSF CTSA) and UL1-TR000454 (Atlanta CTSA).

\section{Conflicts of interest}

The authors report no conflicts of interest.

\section{References}

1. US Department of Health and Human Services. The health consequences of smoking - 50 years of progress: a report of the surgeon general. Atlanta, GA: US Department of Health and Human Services, Centers for Disease Control and Prevention, Coordinating Center for Health Promotion, National Center for Chronic Disease Prevention and Health Promotion, Office on Smoking and Health; 2014, http://www.surgeongeneral.gov/ library/reports/50-years-of-progress/ [Accessed 14 July 2016].

2. Aliyu MH, Weldeselasse H, August EM, Keith LG, Salihu HM. Cigarette smoking and fetal morbidity outcomes in a large cohort of HIV-infected mothers. Nicotine Tob Res 2013; 15:177-184.

3. Pineles BL, Park E, Samet JM. Systematic review and metaanalysis of miscarriage and maternal exposure to tobacco smoke during pregnancy. Am J Epidemiol 2014; 179:807-823.

4. Mclntosh ID. Smoking and pregnancy: I. Maternal and placental risks. Public Health Rev 1984; 12:1-28. 
5. DiFranza JR, Lew RA. Effect of maternal cigarette smoking on pregnancy complications and sudden infant death syndrome. J Fam Pract 1995; 40:385-394.

6. Burton GJ, Palmer ME, Dalton KJ. Morphometric differences between the placental vasculature of nonsmokers, smokers and ex-smokers. Br / Obstet Gynaecol 1989; 96:907-915.

7. Larsen LG, Clausen HV, Jonsson L. Stereologic examination of placentas from mothers who smoke during pregnancy. $A m$ J Obstet Gynecol 2002; 186:531-537.

8. Bush PG, Mayhew TM, Abramovich DR, Aggett PJ, Burke MD Page KR. A quantitative study on the effects of maternal smoking on placental morphology and cadmium concentration. Placenta 2000; 21:247-256.

9. Lehtovirta $P$, Forss $M$. The acute effect of smoking on intervillous blood flow of the placenta. Br J Obstet Gynaecol 1978; 85:729-731.

10. Aisemberg J, Vercelli C, Wolfson M, Salazar AI, Osycka-Salut C, Billi $S$, et al. Inflammatory agents involved in septic miscarriage. Neuroimmunomodulation 2010; 17:150-152.

11. Bansal AS, Bajardeen B, Thum MY. The basis and value of currently used immunomodulatory therapies in recurrent miscarriage. J Reprod Immunol 2012; 93:41-51.

12. Bansal AS. Joining the immunological dots in recurrent miscarriage. Am / Reprod Immunol 2010; 64:307-315.

13. Kwak-Kim J, Park JC, Ahn HK, Kim JW, Gilman-Sachs A. Immunological modes of pregnancy loss. Am I Reprod Immunol 2010; 63:611-623.

14. Salafia C, Shiverick K. Cigarette smoking and pregnancy II: vascular effects. Placenta 1999; 20:273-279.

15. Shiverick KT, Salafia C. Cigarette smoking and pregnancy I: ovarian, uterine and placental effects. Placenta 1999; 20: 265-272.

16. Mdodo R, Frazier EL, Dube SR, Mattson CL, Sutton MY, Brooks $\mathrm{JT}$, et al. Cigarette smoking prevalence among adults with HIV compared with the general adult population in the United States: cross-sectional surveys. Ann Intern Med 2015; 162: 335-344.

17. Goldberg D, Weber KM, Orsi J, Hessol NA, D'Souza G, Watts $\mathrm{DH}$, et al. Smoking cessation among women with and at risk for HIV: are they quitting? J Gen Intern Med 2010; 25:39-44.

18. Sharma A, Feldman JG, Golub ET, Schmidt J, Silver S, Robison E, et al. Live birth patterns among human immunodeficiency virus-infected women before and after the availability of highly active antiretroviral therapy. Am / Obstet Gynecol 2007; 196:541e541-546.

19. Brocklehurst $P$, French $R$. The association between maternal HIV infection and perinatal outcome: a systematic review of the literature and meta-analysis. Br J Obstet Gynaecol 1998; 105:836-848.

20. Massad LS, Springer G, Jacobson L, Watts H, Anastos K, Korn A, et al. Pregnancy rates and predictors of conception, miscarriage and abortion in US women with HIV. Aids 2004; 18: 281-286.

21. Minkoff $H$, Hershow $R$, Watts $D H$, Frederick $M$, Cheng $I$, Tuomala $R$, et al. The relationship of pregnancy to human immunodeficiency virus disease progression. Am / Obstet Gynecol 2003; 189:552-559.

22. Shah MR, Cook N, Wong R, Hsue P, Ridker P, Currier J, et al. Stimulating high impact HIV-related cardiovascular research: recommendations from a multidisciplinary NHLBI Working Group on HIV-related heart, lung, and blood disease. I Am Coll Cardiol 2015; 65:738-744.

23. Lang S, Boccara F, Mary-Krause M, Cohen A. Epidemiology of coronary heart disease in HIV-infected versus uninfected individuals in developed countries. Arch Cardiovasc Dis 2015; 108:206-215.

24. Shirley DK, Kaner RJ, Glesby MJ. Effects of smoking on nonAIDS-related morbidity in HIV-infected patients. Clin Infect Dis 2013; 57:275-282.

25. Kreitchmann R, Li SX, Melo VH, Fernandes Coelho D, Watts $\mathrm{DH}$, Joao $\mathrm{E}$, et al. Predictors of adverse pregnancy outcomes in women infected with HIV in Latin America and the Caribbean: a cohort study. BJOG 2014; 121:1501-1508.

26. Ahern J, Hubbard A, Galea S. Estimating the effects of potential public health interventions on population disease burden: a step-by-step illustration of causal inference methods. $A m$ J Epidemiol 2009; 169:1140-1147.
27. Hessol NA, Weber KM, D'Souza G, Burton D, Young M, Milam $\mathrm{J}$, et al. Smoking cessation and recidivism in the Women's Interagency Human Immunodeficiency Virus Study. Am J Prev Med 2014

28. Westreich D. From exposures to population interventions: pregnancy and response to HIV therapy. $A m$ / Epidemiol 2014; 179:797-806.

29. Barkan SE, Melnick SL, Preston-Martin S, Weber K, Kalish LA, Miotti $P$, et al. The Women's Interagency HIV Study. WIHS Collaborative Study Group. Epidemiology 1998; 9:117-125.

30. Bacon MC, von Wyl V, Alden C, Sharp G, Robison E, Hessol N, et al. The Women's Interagency HIV Study: an observational cohort brings clinical sciences to the bench. Clin Diagn Lab Immunol 2005; 12:1013-1019.

31. Greenland S, Pearl J, Robins JM. Causal diagrams for epidemiologic research. Epidemiology 1999; 10:37-48.

32. Howe CJ, Cole SR, Westreich DJ, Greenland S, Napravnik S, Eron JJ. Splines for trend analysis and continuous confounder control. Epidemiology 2011; 22:874-875.

33. Westreich D, Cole SR. Invited commentary: positivity in practice. Am / Epidemiol 2010; 171:674-677.

34. McEvoy JW, Nasir K, DeFilippis AP, Lima JA, Bluemke DA, Hundley WG, et al. Relationship of cigarette smoking with inflammation and subclinical vascular disease: the Multi-Ethnic Study of Atherosclerosis. Arterioscler Thromb Vasc Biol 2015; 35:1002-1010.

35. Ohkuma T, Iwase M, Fujii H, Kaizu S, Ide H, Jodai T, et al. Doseand time-dependent association of smoking and its cessation with glycemic control and insulin resistance in male patients with type 2 diabetes mellitus: the Fukuoka Diabetes Registry. PLoS One 2015; 10:e0122023.

36. Howards PP, Schisterman EF, Heagerty PJ. Potential confounding by exposure history and prior outcomes: an example from perinatal epidemiology. Epidemiology 2007; 18:544-551.

37. Bagaitkar I, Demuth DR, Scott DA. Tobacco use increases susceptibility to bacterial infection. Tob Induc Dis 2008; 4:12.

38. Weinberg CR. Interaction and exposure modification: are we asking the right questions? Am J Epidemiol 2012; 175:602-605.

39. Greenland S. Interactions in epidemiology: relevance, identification, and estimation. Epidemiology 2009; 20:14-17.

40. Poole C. On the origin of risk relativism. Epidemiology 2010; 21:3-9.

41. Westreich D, Edwards JK, Rogawski ET, Hudgens MG, Stuart EA, Cole SR. Causal impact: epidemiological approaches for a public health of consequence. Am J Public Health 2016; 106:1011-1012.

42. Hoffman AM, Redding CA, Goldberg D, Anel D, Prochaska JO, Meyer PM, et al. Computer expert systems for African-American smokers in physicians offices: a feasibility study. Prev Med 2006; 43:204-211.

43. Redding C, Goldberg D, Weber K, Burke-Miller J, Paiva A, Yin $\mathrm{H}$, et al. Effects of a TTM-tailored smoking cessation pilot study in women smokers with and at risk for HIV. Ann Behav Med 2014; 47(Suppl).

44. Westreich D, Cole SR, Young JG, Palella F, Tien PC, Kingsley L, et al. The parametric g-formula to estimate the effect of highly active antiretroviral therapy on incident AIDS or death. Stat Med 2012; 31:2000-2009.

45. Keil AP, Edwards JK, Richardson DB, Naimi AI, Cole SR. The parametric g-formula for time-to-event data: intuition and a worked example. Epidemiology 2014; 25:889-897.

46. Poole C. Low P-values or narrow confidence intervals: which are more durable? Epidemiology 2001; 12:291-294.

47. Stang A, Poole C, Kuss $O$. The ongoing tyranny of statistical significance testing in biomedical research. Eur J Epidemiol 2010; 25:225-230.

48. Hernán MA. A definition of causal effect for epidemiological research. J Epidemiol Community Health 2004; 58:265-271.

49. Hernán MA, Robins JM. Estimating causal effects from epidemiological data. J Epidemiol Community Health 2006; 60: 578-586.

50. Cole SR, Stuart EA. Generalizing evidence from randomized clinical trials to target populations: The ACTG 320 trial. Am J Epidemiol 2010; 172:107-115.

51. Frangakis $\mathrm{C}$. The calibration of treatment effects from clinical trials to target populations. Clin Trials 2009; 6:136-140. 